Copyright (C 2014 IEEE. Personal use of this material is permitted. Permission from IEEE must be obtained for all other uses, in any current or future media, including reprinting/republishing this material for advertising or promotional purposes, creating new collective works, for resale or redistribution to servers or lists, or reuse of any copyrighted component of this work in other works. 


\section{Distributed Battery Storage Units for Overload Pre- vention in an Islanded Microgrid}

\author{
Megha Goyal, Arindam Ghosh \\ Department of Electrical and Computer Engineering \\ Curtin University, Perth, WA \\ Email: megha.goyal@postgrad.curtin.edu.au
}

\author{
Farhad Shahnia \\ Department of Electrical and Computer Engineering \\ Curtin University, Perth, WA \\ Email: arindam.ghosh@curtin.edu.au
}

\begin{abstract}
In an islanded microgrid, the load demand must be met by the distrusted generators (DGs) connected to it. Usually this can satisfactorily. However load growth increases, especially the peak load. In such a case, more DGs are to be connected to cater to the load growth. Alternatively if the overloading conditions occur infrequently or remain for shorter periods, storage units can be employed. In this paper, distributed battery storage units (BSUs) are employed for the overloading prevention in an islanded microgrid. It has been assumed that the microgrid only contains inertial DGs and ordinarily they share power in a frequency droop control. When an overloading is detected, the BSUs come on line and share power with the DGs using the same frequency droop control. The detection of overloading condition and when overload has been removed are crucial for this operation. An algorithm is proposed for this purpose. Through simulation studies, it has been demonstrated that the BSUs can be switched on and off seamlessly.
\end{abstract}

Keywords: Islanded Microgrid, Battery Storage Units, Diesel Generator and Frequency Droop.

\section{INTRODUCTION}

$\mathrm{I}$ Slanded microgrid successful operation depends on storage units that can quickly come on line during contingencies caused by power shortfall [1-2]. The advantage of a battery storage unit (BSU) is that it can supply power for longer duration of time, when required. Significant voltage and frequency level maintenance is a challenging task in an islanded microgrid. Usually distributed generators (DGs) connected to the microgrid control the frequency and voltage, while supplying the load requirement as per their ratings in a droop control mode [3-4]. In an islanded microgrid, the droop control algorithms facilitate power sharing based only on local measurements without using any communication channel [5].

In an islanded microgrid, DGs size selection must be according to the load demand. It may however be possible that during peak hours, the load demand exceed the total rating of DGs. In this situation, resizing of DGs is not an option. Therefore, islanded microgrid must be equipped with storage units [6]. These units allow reliable operation of islanded microgrid while avoiding the need of new DG connection [7]. Moreover, they can improve the voltage stability and eliminate the power quality disturbance [8].

Various kind of technologies based storage unit can be used. For example: Pumped Hydroelectric Storage, Compressed Air Energy Storage system, Flow Battery, Fuel Cell, Solar Fuel, Superconducting Magnetic Energy Storage system, Flywheel, Capacitor, Supercapacitor, Thermal Energy
Storage system and Battery [9]. In this paper, battery storage units (BSUs) are considered to prevent the overload situation. They must come online in system quickly and go offline without any disturbance. From that point of view, the BSUs must float in the system and not get connected through switches. Furthermore, there may be several BSU units distributed throughout the microgrid.

If the BSUs start supplying their maximum capacity as determined by their state of charge (SOC) [10-11], and there is sufficient number of them connected to the microgrid, the system collapse due to overloading will be prevented. In that case, BSUs will discharge quickly and will not be able to sustain if the overload condition persists for a longer period of time. It is therefore desirable that the BSUs also share power according to their rating (SOC) with the other DGs.

In this paper, a new control strategy is proposed for BSUs to prevent the overloading in an islanded microgrid. The microgrid consists only inertial sources to supply load and they share power supply in a frequency droop. The BSUs are usually floating on the microgrid bus. When they are connected, they share power with other DGENs using the same frequency droop. To match the response of BSUs with inertial sources, a pseudo inertia concept is used [12]. Several numerical examples are presented to validate the proposal.

\section{MICROGRID STRUCTURE}

The study system of islanded microgrid is considered with two diesel generators (DGEN-1 and DGEN-2) and load. This microgrid also consists floating battery storage units (BSUs) for overload prevention. These BSUs nominally float on the microgrid bus neither consuming nor supplying power. However, they can come online quickly and seamlessly whenever there is an overload event. They also get automatically disconnected when overloading condition is vanished. In Fig.1, DGEN-1 and DGEN-2 supply real power $P_{1}$ and $P_{2}$ respectively according to their rating. $Q_{1}, Q_{2}$ are their respective reactive powers. Microgrid local load power is represented by $P_{L}, Q_{L}$. Also denoted in Fig.1, the buses at which the DGENs and BSUs are connected. The parameters of DGEN-1 and DGEN-2 are given in the Appendix.

\section{A. DGEN Control}

A dispatchable source (DGEN) in the microgrid is controlled through a frequency droop, given by [13] 


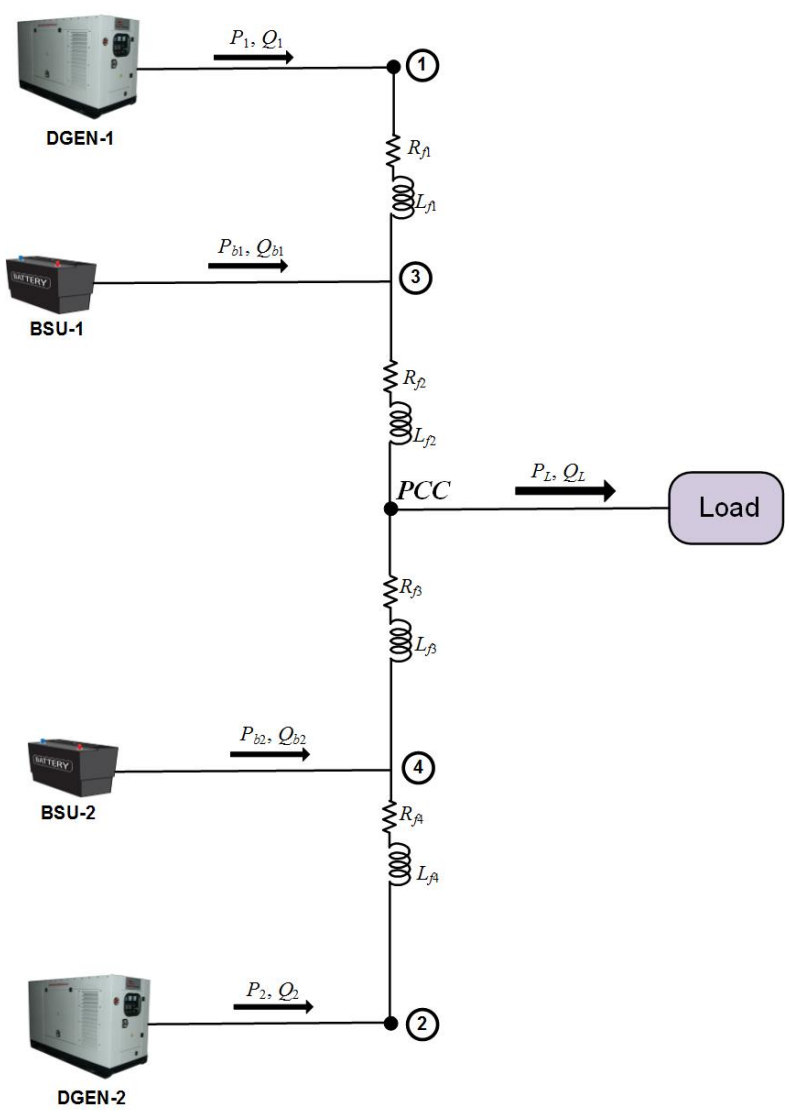

Fig. 1. Islanded microgrid structure.

$$
\begin{aligned}
& \omega=\omega_{r}+m \times\left(0.5 P^{*}-P\right) \\
& V=V_{r}+n \times\left(Q^{*}-Q\right)
\end{aligned}
$$

where

- $\omega_{r}$ and $\omega$ are the rated and actual frequency of the DGEN respectively.

- $\quad P^{*}$ and $P$ are rated and actual measured real power of the DGEN.

- The frequency droop coefficient is $m$.

- $\quad V_{r}$ and $V$ are the rated and actual voltage of the DGEN respectively.

- $Q^{*}$ and $Q$ are rated and actual measured reactive power of the DGEN.

- $\quad n$ is the voltage droop coefficient.

The diesel generator set configuration with reciprocating internal combustion (IC) engine is shown in Fig. 2. The fuel rate of prime mover IC engine is controlled by the governor. The governor senses the actual speed of generator shaft and maintains it to the reference level $(\omega)$, which is calculated from the frequency droop control (1). This generator set consists automatic voltage regulator (AVR) which controls its internal voltage [14]. Thus, real and reactive power of DGEN is controlled from governor and AVR respectively.

To control the reactive power flow in system, the output voltage of DGENs must be different from the voltage of the buses to which they are connected. To achieve this, the generator output voltage must be controlled. The controller configuration is shown in Fig. 3. The measured reactive power $Q$ is compared with its desired value $Q^{*}$. The error is attenuated through the gain $K$ and is added with the difference between the reference voltage of the bus where the DGEN is connected $\left(V_{b u s}{ }^{*}\right)$ and its measured value $\left(V_{b u s}\right)$, A PI controller is then used to obtain the reference voltage magnitude $\left(V^{*}\right)$. This reference is the input voltage to AVR of DGENs.

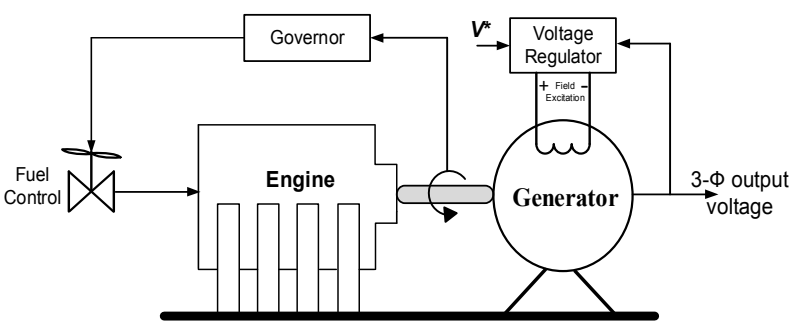

Fig. 2. Diesel generator set with reciprocating internal combustion engine.

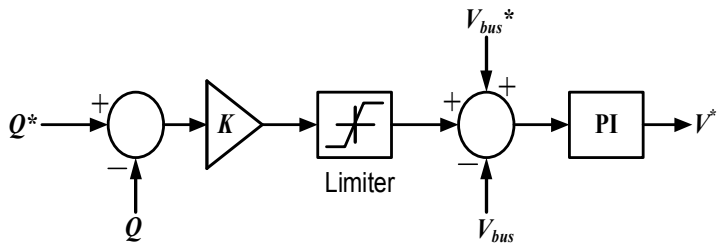

Fig. 3. Reference voltage calculation scheme.

In the islanded microgrid under consideration, local loads are supplied from DGENs only. This implies that the DGENs can supply only up to their rated power. However, the peak load demand can increase more than that their total rated power. In this case a catastrophic failure will occur in the system. The following example illustrates it.

Example 1: Let us consider the system of Fig. 1, where the ratings of DGEN-1 and DGEN-2 are $500 \mathrm{~kW}$ and $250 \mathrm{~kW}$ respectively. The droop parameters of the DGENs are chosen such that the frequency excursion is limited to $\pm 0.3 \mathrm{~Hz}$ from the nominal value of $50 \mathrm{~Hz}$. It means that DGENs supply their maximum rated power at $49.7 \mathrm{~Hz}$ frequency and supply zero power at $50.3 \mathrm{~Hz}$ frequency.

At the beginning the local load in microgrid is assumed to be $700 \mathrm{~kW}$. The DGENs operate in frequency droop to share the power according to their rating. It is shown in Fig. 4, where the power supplied from DGEN-1 is twice that of DGEN-2. At $5 \mathrm{~s}$, the local load demand is increased by 150 $\mathrm{kW}$. Therefore, load demand is higher than the total DGEN rating. As it can be seen in Fig. 4 that due to of inertias, the DGENs start releasing their stored kinetic energy to support the load demand. However, the DGEN speeds, shown in Fig. 5 , keep on dropping till $16.8 \mathrm{~s}$, after which a catastrophic failure occurs. This causes both voltage (shown in Fig. 6) and power (Fig. 4) to collapse. It is to be noted that this behavior is shown for demonstration purpose. In practice however, the under frequency relays will trip the DGEN much before the collapse can occur.

This overloading can be prevented by inserting BSUs in the microgrid. These units can come quickly online when required; otherwise they float on the system. The switching ON and OFF of the BSUs will be discussed in session III. To match the speed response of BSUs, with these of DGENs, the procedure used is discussed below. 


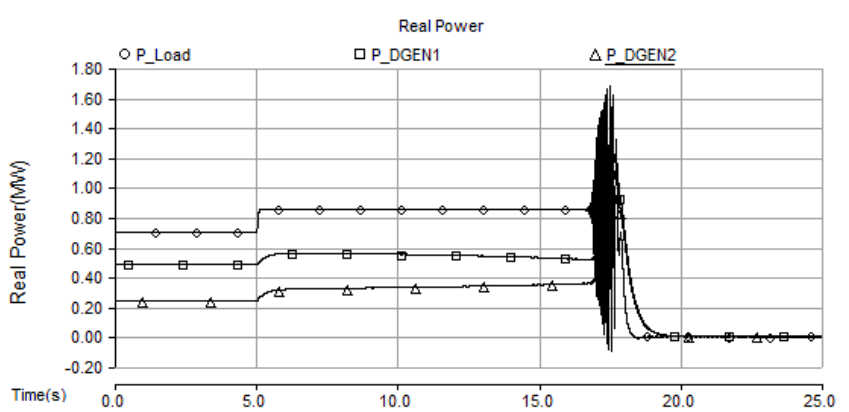

Fig. 4. Real power flow in system.

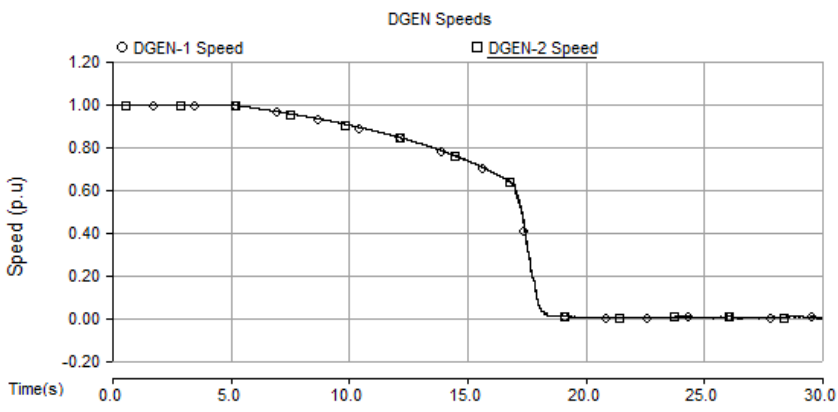

Fig.5. Speed of DGENs during overloading.

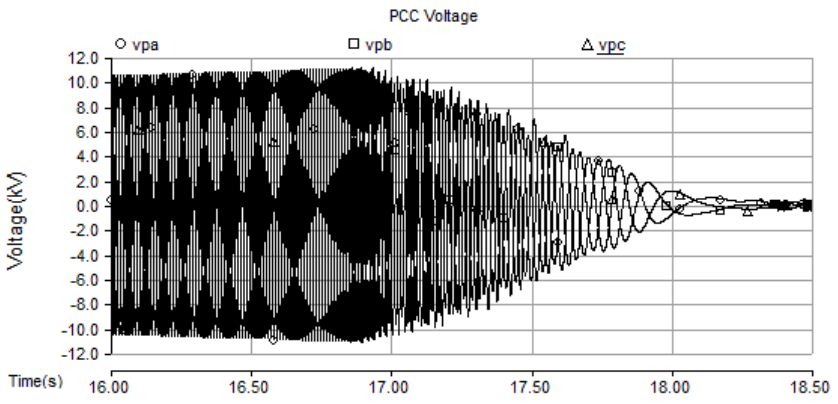

Fig. 6. PCC voltage during overload.

\section{B. BSUs Control}

BSUs are converter interfaced sources. The time response of BSU is faster than the DGENs. Therefore, pseudo inertia is introduced to slow down its response.

Once, BSUs are connected in microgrid then they also operate in same frequency droop control and to share their real powers according to their rating. The calculation of droop coefficients is discussed in [15]. These are given in Table I in Appendix.

With the pseudo inertia, a BSU generates a set of voltages that mimics the operation of a classical machine through the solution of the swing equation as shown in Fig. 7. In this figure, mechanical power $\left(P_{m}\right)$ is calculated from the reference power, used in (1) and error in frequency as given in Eq. 3 [16].

$$
P_{m}=\frac{G}{1+s T} P^{*}-D \Delta \omega
$$

where $\omega$ is obtained from droop (1) and

$$
D=\frac{1}{m}, \quad \Delta \omega=\omega-\omega_{r}
$$

This mechanical power is used to solve the swing equation, given by

$$
\begin{aligned}
& \frac{d \delta}{d t}=\omega_{r} \Delta \omega_{s w} \\
& \frac{d \Delta \omega_{s w}}{d t}=\frac{1}{2 H}\left(-K_{D}\right) \Delta \omega_{s w}+\frac{1}{2 H}\left(P_{m}-P\right) \\
& \omega_{B S U}=\omega+\Delta \omega_{s w}
\end{aligned}
$$

where $K_{D}$ and $H$ are the damping ratio and inertia constant respectively. These parameters are given in Table III in Appendix. $\omega_{B S U}$ is the frequency for reference voltage of the converter. Thus, the output of the swing are then used to generate the reference voltages of the BSU as

$$
\begin{aligned}
& v_{B S U a}^{*}=V^{*} \sin \left(\omega_{B S U} t+\delta\right) \\
& v_{B S U b}^{*}=V^{*} \sin \left(\omega_{B S U} t+\delta-120^{\circ}\right) \\
& v_{B S U c}^{*}=V^{*} \sin \left(\omega_{B S U} t+\delta+120^{\circ}\right)
\end{aligned}
$$

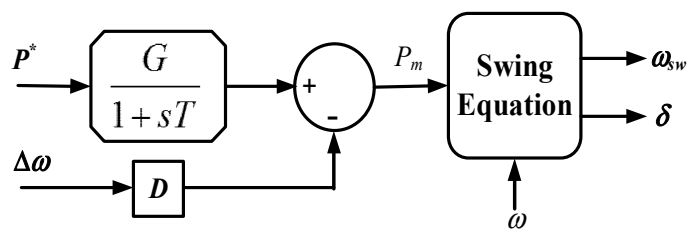

Fig. 7. Pseudo inertia for BSU.

An output feedback voltage controller is used to track these reference voltages [17] by VSC. The VSC structure and control are discussed in [18] and are not presented here.

\section{BSUs SWITCHING ALGORITHM}

\section{A. BSU Turn ON}

In a microgrid, the load can be dispersed. Therefore if overload were to be detected by power consumption only, an aggregator and communication will be required. These may not be readily available. To avoid this, in this paper, an algorithm is designed in which frequency is the detecting signal for overload protection. As mentioned before, the microgrid frequency excursion limit is $\pm 0.3 \mathrm{~Hz}$. Also it has been mentioned that if system frequency is $49.7 \mathrm{~Hz}$, then DGENs operate at their rated power to supply local load plus losses. Also it can be seen from Fig. 4 to 6 that the DGENs can supply an overload for over $10 \mathrm{~s}$. This provides sufficient time for the BSUs to come online. We have chosen a frequency threshold of 49.71 $\mathrm{Hz}$. This implies that as system frequency hits this threshold value of frequency, the power supplied from DGEN's at its maximum and further increment in load will cause system collapse. Therefore, this is the trigger signal for BSU turn ON.

Once BSUs are turned-on, they operate in same frequency droop to supply power according to their current rated power rather than supplying fixed amount of power. Therefore, system frequency will rise above the threshold value. Hence, it is crucial that they do not switch off immediately. This is discussed in sub-section III-c.

\section{B. BSU Turn OFF}

As the load demand reduces, BSUs should either be charged or come off from the grid. The turn off signal for BSUs can also be detected from the system frequency. The threshold value of frequency for turn-off signal depends on the power sharing ratio of the sources. In the microgrid, the maximum rated power of DGEN-1, DGEN-2, BSU-1 and BSU-2 respec- 
tively are $500 \mathrm{~kW}, 250 \mathrm{~kW}, 50 \mathrm{~kW}$ and $100 \mathrm{~kW}$. Therefore the power sharing ratio of BSU-1: BSU-2: DGEN-2: DGEN-1 is $1: 2: 5: 10$. Let us now assume that the load demand has dropped to or below $750 \mathrm{~kW}$ when the over loading condition is over. The BSUs still keep on supplying power as they share power in droop. Obviously, the BSUs should cut off when the load is $750 \mathrm{~kW}$. During this time, DGEN-1 supplies $(10 / 18) \times$ $750 \mathrm{~kW}$, while it should be ideally supplying $500 \mathrm{~kW}$. Therefore the frequency of DGEN-1 for this level of power supply is

$$
f_{\text {th }}=50+\frac{0.0075 \times(0.5 \times 500-416.66)}{2 \pi}=49.80 \mathrm{~Hz}
$$

If the load demand is less than $750 \mathrm{~kW}$, or system frequency will be less than $f_{t h}$. In this case, BSUs are not required in system to supply load demand. Therefore, $f_{t h}$ is considered to be the threshold value of frequency to turn off the BSU. Also note that once the BSUs switch off, the system frequency may fall below $f_{t h}$. To prevent this, a debouncing type state machine is designed, as discussed next.

\section{STATE MACHINE FOR BSU SWITCHING}

The designed state machine has two states $\mathrm{X}_{1}$ and $\mathrm{X}_{2}$, two inputs $\omega_{1}$ and $\omega_{2}$ and output $A / \bar{D}$ as shown in Fig. 8. The signal $\omega_{1}$ is generated when the droop frequency falls below a threshold frequency $49.71 \mathrm{~Hz}$. The signal $\omega_{2}$ is generated when the droop frequency rises above $49.8 \mathrm{~Hz}$. Initially, the state machine is idle with $\mathrm{X}_{1} \mathrm{X}_{2}=00$. When overloading occurs $\omega_{1}$ becomes 1 while $\omega_{2}$ remains 0 . The state moves to $\mathrm{X}_{1} \mathrm{X}_{2}=01$ and the output $A / \bar{D}$ becomes 1 . As soon as the battery is de-blocked, some transient may cause $\omega_{1}$ to become 0 . However, this does not mean that the overloading is removed. Therefore, state moves to $\mathrm{X}_{1} \mathrm{X}_{2}=11$ and the output still remains $A / \bar{D}=1$. Once the transient is over and battery is firmly connected, $\omega_{1}$ becomes 0 since frequency is higher than threshold value $49.8 \mathrm{~Hz}$. In this case, state will settle to $\mathrm{X}_{1} \mathrm{X}_{2}=11$. When the overloading is removed then $\omega_{2}$ becomes 1 and states moved to $\mathrm{X}_{1} \mathrm{X}_{2}=10$. The output become $A / \bar{D}=0$. The transient event will be taken care by debouncing and bouncing between $\mathrm{X}_{1} \mathrm{X}_{2}=10$ and 00 .

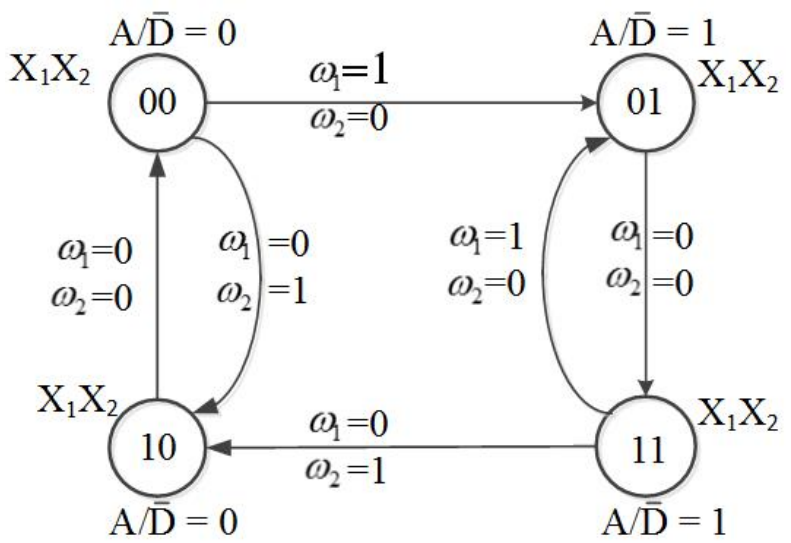

Fig. 8. State machine diagram for switching control.

The state machine can be realized by two JK flip-flop with the inputs [19].

\section{BATTERY CHARGING STRATEGY}

BSUs can be charged from DGENs during the off peak times for use during peak load event. However, it has been notified that system operates in frequency droop control. When the frequency is $50 \mathrm{~Hz}$, DGENs supply their half of their rated power. Therefore, when the system frequency is 50 $\mathrm{Hz}$ or more, the microgrid load demand is half or less than half of its total capacity. This can be defined as off-peak time. Therefore, the BSUs can be charged when the frequency is 50 $\mathrm{Hz}$ or above.

\section{NUMERICAL EXAMPLES}

Example 2 (BSU Connection): It is assumed that the microgrid is operating stably at beginning supplying $550 \mathrm{~kW}$. The DGENs share load power according to their rating (i.e. $2: 1$ ). The load demand increases at $1.0 \mathrm{~s}$ to $800 \mathrm{~kW}$, which is higher than the total rating of the DGENs. The BSUs get turned-on to prevent the overloading. The real powers are shown in Fig. 9. The frequencies are shown in Fig. 10. It can be seen that the frequencies of all the units merge in the steady state. The PCC (load bus) voltages are maintained sinusoidal as shown in Fig. 11.

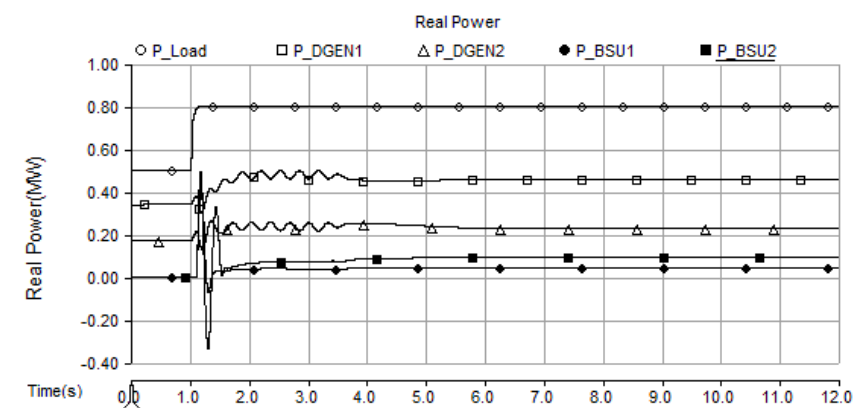

Fig. 9. Real power sharing in microgrid with BSUs (Example-2).

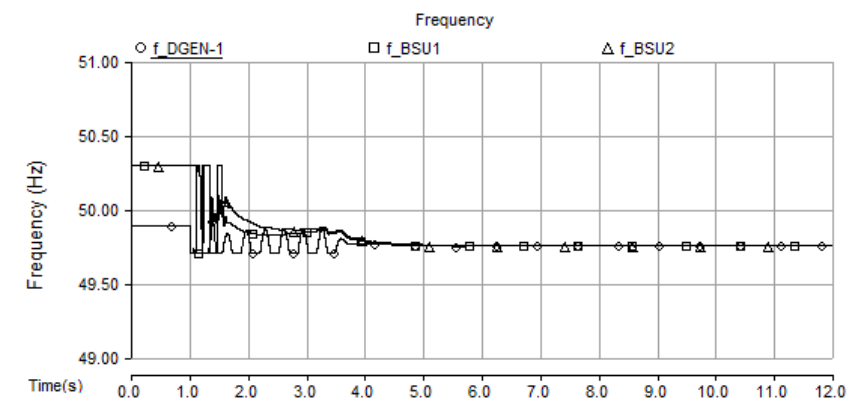

Fig. 10. Frequencies of BSUs and DGEN-1 (Example-2).

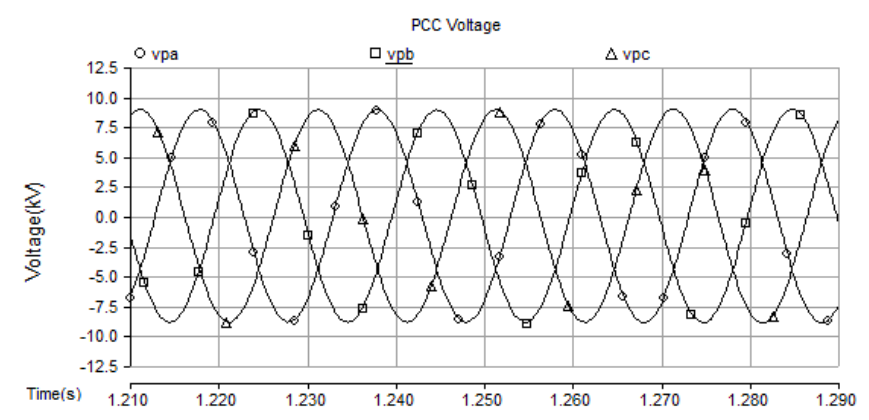

Fig. 11. PCC voltage (Example-2).

Example 3 (BSU Disconnection): Starting with Example 2, where the total load was $800 \mathrm{~kW}$, the load reduces by $100 \mathrm{~kW}$. 
This is shown in Fig. 12. Even though the DGENs can by them-selves supply the load demand, the BSUs still remain connected, as can be seen from this figure. The frequencies of the DGEN-1 and the two BSUs are shown in Fig. 13. The system frequency reaches $49.8 \mathrm{~Hz}$ at around $13.8 \mathrm{~s}$, at which point, the BSUs are turned off.

The real powers when the BSUs turn off are shown in Fig. 14. It can be seen when they turn off, the powers supplied by the DGENs increase. The frequencies of the DGEN-1 and the two BSUs are shown in Fig. 15. It can be seen that the BSU frequencies hit the upper limit as they are not supplying any amount of power. The PCC voltages at the point of BSU disconnection are shown in Fig. 16. Since they do not undergo any large transient or sag/swell, the can be surmised that the BSUs disconnection is seamless.

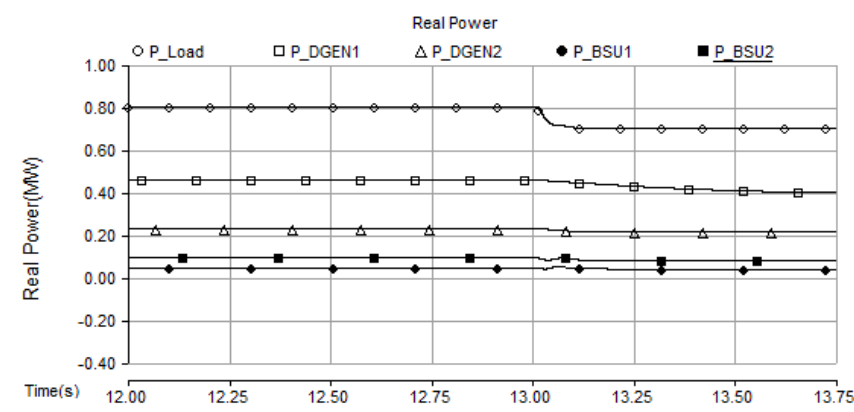

Fig. 12. Real power sharing in microgrid with BSUs (Example-3).

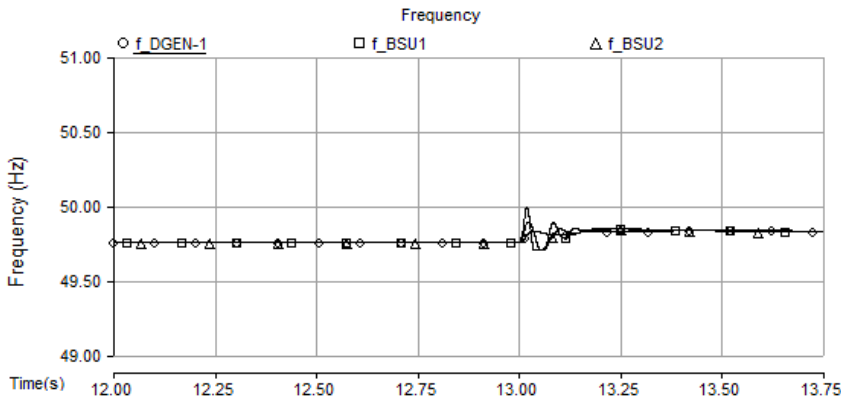

Fig. 13. Frequencies of BSUs and DGEN-1 (Example-3).

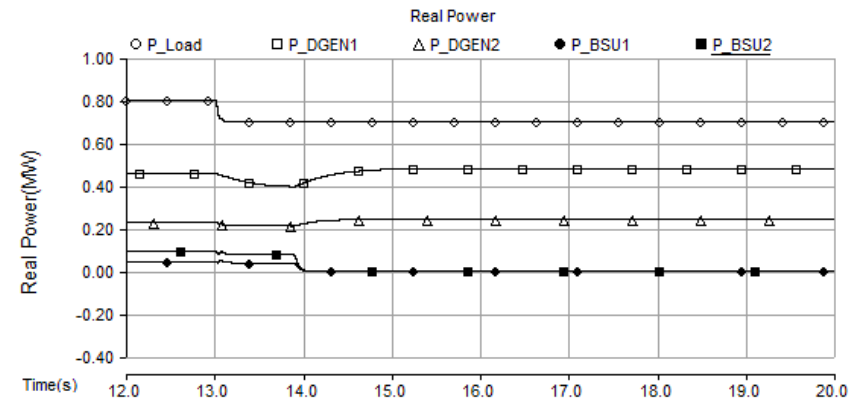

Fig. 14. Real power flow when BSUs are disconnected (Example-3).

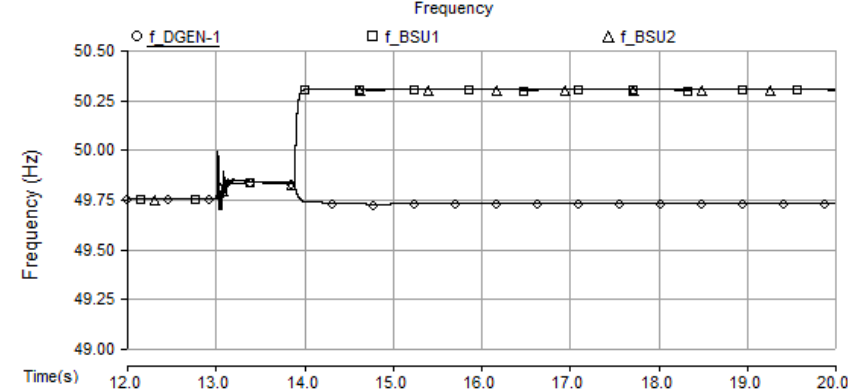

Fig. 15. Frequencies of BSUs and DGEN-1 (Example-3).

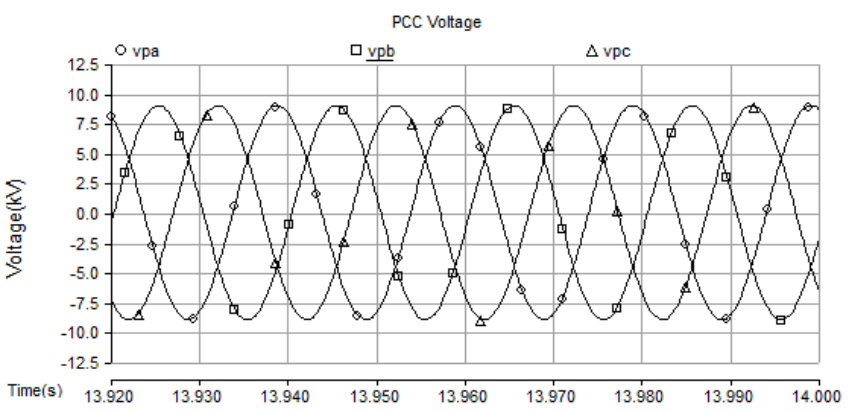

Fig. 16. PCC voltage (Example-3).

Example 4 (BSU Charging): In this Example, a case is considered when microgrid load is off peak. In Fig. 17, it is shown that load demand is $250 \mathrm{~kW}$, where both DGENs are supplying power less of their half of rated and the system frequency is greater than $50 \mathrm{~Hz}$. It is shown in Fig. 18. Therefore, at $5 \mathrm{~s}$, BSUs are connected to the microgrid for charging. It can be seen from Fig. 17 that both the BSU powers are negative, indicating the BSUs are drawing power. This causes the system frequency to reduce as can be seen in Fig. 18.

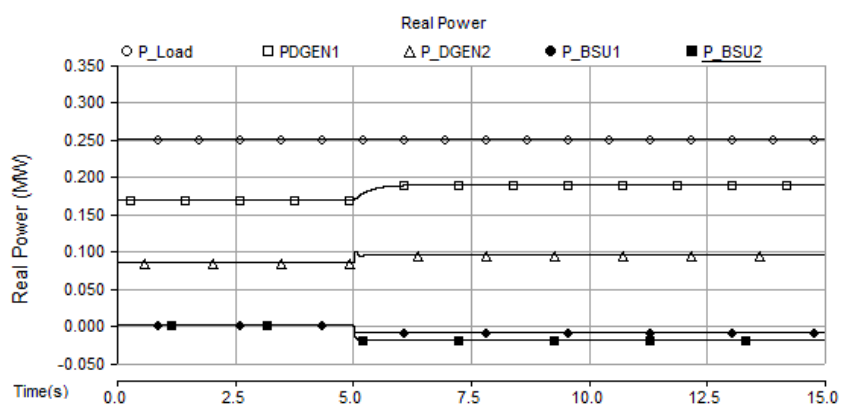

Fig. 17. Off peak load power and BSUs charging (Example-4)

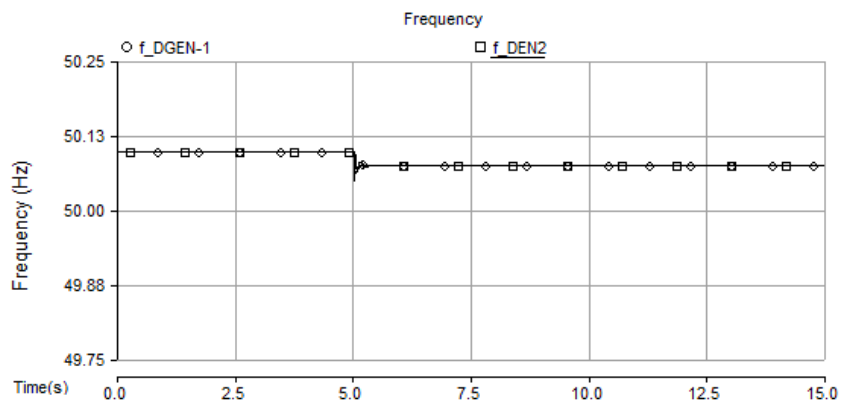

Fig. 18. Frequencies of DGEN-1 and DGEN-2 (Example-4). 


\section{CONCLUSIONS}

In this paper, a new algorithm is proposed for connection/disconnection of BSUs for overload prevention in an islanded microgrid. This algorithm provides seamless connection or disconnection of the BSUs. The BSUs operate in a frequency droop, in the same manner as the dispatchable generators in the microgrid. A pseudo inertia concept is used to make the BSU response compatible with inertial generators. Some numerical examples are presented to elucidate the veracity of the algorithm using PSCAD.

\section{ACKNOWLEDGEMENT}

The authors thank the Australian Research Council (ARC) for the financial support for this project through the ARC Discovery Grant DP110104554.

\section{REFERENCES}

[1] S. Chowdhury, S. P. Chowdhury, and P. Crossley, Microgrids and Active Distribution Networks, UK: Institution of Engineering and Technology, 2009, pp. 57-76.

[2] A. M. Borbelyand and J. F. Kreider, Distributed Generation: The Power Paradigm for the New Millennium, CRC, New York, 2001.

[3] F. Katiraei, and M.R. Iravani, "Power management strategies for a microgrid with multiple distributed generation units," IEEE Trans. on Power System, vol. 21, no. 4, pp. 1821-1831, Nov. 2006.

[4] J.A.P. Lopes, C.L. Moreira and A.G. Madureira, "Defining control strategies for microgrids islanded operation," IEEE Trans. on Power Systems, vol. 21, no. 2, pp. 916-924, 2006.

[5] De Brabandere, K, Bolsens Bruno, Van den Keybus, J, Woyte A, Driesen J, and Belmans R, "A Voltage and Frequency Droop Control Method for Parallel Inverters," IEEE Trans. on Power Electronics, vol.22, no.4, pp.1107-1115, July 2007.

[6] M. R. Islam and A. H. Gabbar, "Study of microgrid safety and protection strategies with control system infrastructures," Smart Grid and Renewable Energy, pp. 1-9, 2012.

[7] T. Considine, W. Cox, and E. G. Cazalet, "Understanding Microgrids as the Essential Architecture of Smart Energy," Grid Inerop Forum, Texas, Dec. 2012.

[8] Mohd A, Ortjohann E, Schmelter A, Hamsic N, and Morton D, "Challenges in integrating distributed Energy storage systems into future smart grid," Industrial Electronics, IEEE International Symposium on, pp.1627-1632, June 30-July 22008.

[9] H. Chen, T. N. Cong, w. Yang, C. Tan Y. Li, and Y. Ding, "Progress in electrical energy storage system: A critical review," Progress in Natural Science, Elsevier, vol. 19, issue 3, pp. 291-312, March 2009.

[10] Wen-Yeau Chang, "The State of Charge Estimating Methods for Battery: A Review," ISRN Applied Mathematics, vol. 2013, Article ID 953792, 7 pages, 2013.

[11] S. Piller, M. perron and A. Jossen, "Methods for state-of-charge determination and their applications," Journal of Power Sources, Elsevier, vol. 96, issue 1, pp. 113-120, June 2001.

[12] M. Goyal, A. Ghosh and F. Zare, "Power Sharing Control with Frequency Droop in a Hybrid Microgrid," IEEE Power and Energy Society General Meeting, July 2013.

[13] P. Kundur, Power System Stability and Control, McGraw-Hill, New York, 1994.

[14] F. Katiraei, R. Iravani, N. Hatziargyriou, and A. Dimeas, "Microgrids management," Power and Energy Magazine, IEEE, vol.6, no.3, pp.54,65, May-June 2008.

[15] M. Goyal and A. Ghosh, "A Phase-Locked-Loop Design for the Smooth Operation of a Hybrid Microgrid," Australian Universities Power Engineering Conference (AUPEC), Tasmania, 2013.

[16] D. J. Glover, S. M Sarma and J. T. Overbye, Power System Analysis and Design, Cengage Learning, Stamford, CT, USA, 2012.

[17] A. Ghosh and G. Ledwich, Power Quality Enhancement Using Custom Power Devices. Boston, MA: Kluwer, 2002, pp. 241-331.
[18] A. Ghosh, "Performance study of two different compensating devices in a custom power park," Proc. IEE Generation, Transmission \& Distribution, vol. 152, no. 4, pp. 521-528, 2005.

[19] G.S. Hope, Integrated Devices in Digital Circuit Design, John Wiley \& Sons, 1981.

\section{APPENDIX}

The system parameters used in the studies presented in this paper are listed in Tables I to VI.

TABLE I: DGs ConNected TO THE Microgrid.

\begin{tabular}{|l|l|}
\hline System Quantities & Values \\
\hline $\mathrm{DG}_{1}$ Feeder impedance & $R_{f 1}=3.025 \Omega, L_{f 1}=57.8 \mathrm{mH}$ \\
\hline $\mathrm{DG}_{2}$ Feeder impedance & $R_{f 2}=3.025 \Omega, L_{f 2}=57.8 \mathrm{mH}$ \\
\hline $\mathrm{DG}_{3}$ Feeder impedance & $R_{f 3}=3.025 \Omega, L_{f 3}=57.8 \mathrm{mH}$ \\
\hline DG Rated Power & $\begin{array}{l}\text { DGEN-1: } 500 \mathrm{~kW} \\
\text { DGEN-2: } 250 \mathrm{~kW}\end{array}$ \\
\hline BSUs Rating & $\begin{array}{l}\text { BSU-1: } 50 \mathrm{~kW} \\
\text { BSU-2: } 100 \mathrm{~kW}\end{array}$ \\
\hline Droop Coefficient (Frequency-Voltage) \\
\hline$m_{1}$ & $0.0075 \quad \mathrm{rad} / \mathrm{MWs}$ \\
\hline$m_{2}$ & $0.015 \mathrm{rad} / \mathrm{kWs}$ \\
\hline$m_{b 1}$ & $0.075 \mathrm{rad} / \mathrm{MWs}$ \\
\hline$m_{b 2}$ & $0.15 \mathrm{rad} / \mathrm{kWs}$ \\
\hline$n_{1}$ & $0.02 \mathrm{kV} / \mathrm{MVAr}$ \\
\hline$n_{2}$ & $0.04 \mathrm{kV} / \mathrm{MVAr}$ \\
\hline
\end{tabular}

TABLE II: Diesel Generator set Data.

\begin{tabular}{|l|l|}
\hline System data & Value \\
\hline Rated voltage & $11 \mathrm{KV}$ \\
\hline Rated frequency & $50 \mathrm{~Hz}$ \\
\hline Rated speed & $1500 \mathrm{rpm}$ \\
\hline Reactance & Value (per unit) \\
\hline$X_{d}$ & 0.116 \\
\hline$X_{d}^{\prime}$ & $7.4 \times 10^{-3}$ \\
\hline$X^{\prime \prime}{ }_{d}$ & $2.94 \times 10^{-3}$ \\
\hline$X_{q}$ & $6.37 \times 10^{-3}$ \\
\hline$X_{q}^{\prime \prime}$ & $5.24 \times 10^{-3}$ \\
\hline$X_{2}$ & 0.044 \\
\hline$X_{0}$ & $2.45 \times 10^{-3}$ \\
\hline Time constants & Value (ms) \\
\hline$t_{d}^{\prime}$ & 25 \\
\hline$t^{\prime \prime}$ & 25 \\
\hline$t_{d 0}^{\prime}$ & 368 \\
\hline$t_{a}$ & 4 \\
\hline
\end{tabular}

TABLE III: Swing Equation Parameters For BSUs

\begin{tabular}{|l|l|}
\hline \multicolumn{1}{|c|}{ System data } & Value \\
\hline Damping constant $\left(K_{D l}\right)$ & $5 \mathrm{MWs} / \mathrm{rad}$ \\
\hline Inertia constant $\left(H_{l}\right)$ & $2 \mathrm{MJ} / \mathrm{MVA}$ \\
\hline Damping constant $\left(K_{D 2}\right)$ & $2.5 \mathrm{MWs} / \mathrm{rad}$ \\
\hline Inertia constant $\left(H_{2}\right)$ & $1 \mathrm{MJ} / \mathrm{MVA}$ \\
\hline
\end{tabular}

